This item was submitted to Loughborough's Research Repository by the author.

Items in Figshare are protected by copyright, with all rights reserved, unless otherwise indicated.

\title{
Weave as a method of sandal design: Innovation through the integration of a hands-on woven textile approach
}

PLEASE CITE THE PUBLISHED VERSION

\section{PUBLISHER}

International European Academy of Design Conference

\section{VERSION}

AM (Accepted Manuscript)

\section{PUBLISHER STATEMENT}

This work is made available according to the conditions of the Creative Commons Attribution-NonCommercialNoDerivatives 4.0 International (CC BY-NC-ND 4.0) licence. Full details of this licence are available at: https://creativecommons.org/licenses/by-nc-nd/4.0/

\section{LICENCE}

CC BY-NC-ND 4.0

\section{REPOSITORY RECORD}

Gordon, Jenny, Faith Kane, and Mark A. Evans. 2019. "Weave as a Method of Sandal Design: Innovation Through the Integration of a Hands-on Woven Textile Approach". figshare. https://hdl.handle.net/2134/22334. 


\section{ABSTRACT Jenny Gordon}

As digital design Faith Kane
make increasing Mark Evans
contributions to
practice, the
hands-on form-
continues to be
Due to this

\author{
Loughborough University \\ Loughborough University \\ Loughborough University
}

L.Gordon@lboro.acuk

F.E.Kane2@lboro.ac.uk

M.A.Evans@lboro.acuk

creative

role of

giving

challenged.

digitisation

progressing, it is timely to reflect on the significance of craft-based approaches. The paper investigates the opportunities afforded by craft-based woven textile approaches for the design of 'ready-to-wear' sandals. The research questions for the study are: what is the associated sandal market and current status of footwear/woven textile design; what are the benefits and drawbacks of a hands-on/craft-based approach to footwear design; and does the approach have the potential to facilitate innovation in sandal design? Current processes, products and markets are outlined and approaches discussed via a literature review. The benefits, drawbacks and potential for innovation are discussed and evaluated with regards to the literature. This is supported by empirical evidence gained via an action research case study that incorporated design practice. The findings indicate that there are benefits associated with a craft-based approach to footwear design, including those for mass manufacturing. Key advantages include facilitating an in-depth understanding of construction and materials, which has potential to lead to innovation. However, the research findings also indicate difficulties that must be overcome including but not limited to, timescales, cost and access to equipment/materials. It is also noted that the use of such approaches is not always viable, especially in extremely low-cost markets.

Keywords: craft-based design, woven textiles, footwear, hands-on processes

\section{I NTRODUCTI ON}

Hands-on interaction with material leads to the acquisition of knowledge (Cross, 2001, p. 54-55; Leader, 2010, p. 408; Philpott, 2012, p. 56; Sweet, 2013, p. 32) and has the potential to facilitate innovation and creativity (Yair and Schwarz, 2011, p.312; Treadaway, 2007, p.35). Wallace et al. describe how "craft finds beauty and design puts that beauty to work" (2004, p.44). This principle has great relevance to this study and the exploration of what utilisation of craft-based textile processes can bring to design for mass manufacture.

The proposal of an approach that is applicable to industry is an important aspect of this research. Investigation of footwear markets revealed opportunities within the 'ready-to-wear' sandal market. A study of textile manufacturing exposed narrow weaving as having potential to be an appropriate method of manufacture for sandal uppers, with benefits in high levels of automation and flexibility of structure. However, further empirical research is required in order to test its suitability.

An action research case study revealed a key advantage of hands-on approaches is gaining in-depth knowledge; this is supported by the findings of the literature review. Potential was identified in using knowledge gained to exploit the properties of materials and constructions. Providing a catalyst for innovation, which may be beyond that experienced through representational approaches to design.

\section{PRODUCTS AND MARKETS}

\subsection{SANDALS}

Thornton (1970, p.21-23) presents the theory that any modern sandal can be classified in terms of a small number of basic types that are taken from the traditional footwear of different cultures. This is based on the premise that all methods of attaching a sole to the foot have been discovered since the first production of sandals in 3500 B.C. (O'Keeffe, 1996, p.22). Schaffer et al. (2012, p.132) state the importance for designers to have knowledge of basic types of footwear, and reinforce that even the most directional designs are likely to refer back to a traditional style. A list combining the categories defined by Thornton and Schaffer et al. is outlined below. 


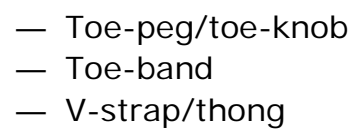

$$
\begin{aligned}
& \text { - Sling-back } \\
& \text { - Multi-strap } \\
& \text { - Peep-toe }
\end{aligned}
$$

When referring to footwear in terms of a fashion product, three main market categories can be identified: bespoke/haute couture, ready-to-wear/prêt-a-porter and mass-produced (Waddell, 2004, p.ix).

Within the ready-to-wear sector, novel/innovative design and quality are driving factors, but unlike bespoke/haute couture footwear designs are produced on a mass-scale. This makes them accessible to a wide customer base (Verdu-J over et al., 2008, p.1881). The mass-produced market is not suitable in terms of timescale and efficiency as emphasis lies in price (Verdu-J over et al., 2008, p.1881) and speed to market (Cohen, 2011, p. 12; Patriquin, 2012, p. 41).

\subsection{TEXTILES}

Wilson (2001, p.13) divides textiles into two categories, "constructed" and "printed". Constructed describes fabrics that are designed by determining their construction. Printed describes a fabric that has been worked into or embellished to generate a new design.

Narrow fabrics are an example of a constructed textile, woven in narrow widths. From around 1650 it has been possible to produce several woven tapes on a single loom, a process that can be mechanised (Thompson et al., 1952 , p.14). Automation along with the potential for creating a number of woven structures make this method of production viable for the ready-to-wear sandal market.

Potential structures for use in sandal design have been identified as follows:

1. Open structures and leno - open structures lend themselves to the open nature of sandals.

2. Multiple cloths - multiple straps may be constructed in this way.

3. Figured - for the introduction of pattern and trapping weft yarns to be introduced as straps.

The way in which a loom is set up is dependent on the desired weave structure. Analysing relevant structures is not only important when considering manufacture, it also provides design inspiration. Through the imposition of technical parameters, the designer can focus on the design possibilities that are available within the constraints (Shillito et al., 2001, p.199). Classifications of narrow fabric are shown in Figure 1.

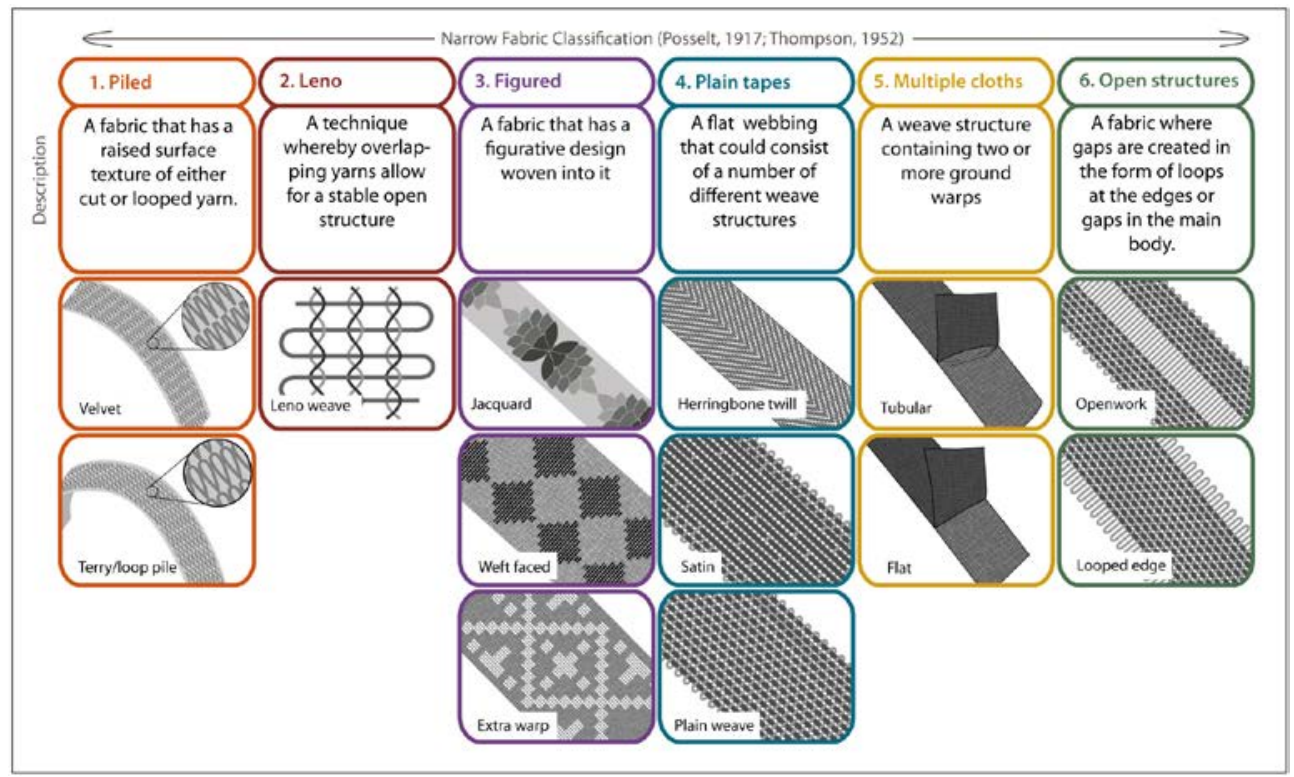

Figure 1- A taxonomy of narrow fabrics 


\section{Weave as a method of sandal design: I nnovation through the integration of a hands-on woven textile approach}

\section{DESI GN PROCESSES}

Design is a decision making process, using creative problem solving (Collis et al., 2007, p.2) in order to realise ideas, transform them into products (Wilson, 2001, p.13) and create a solution to a design problem (Lawson et al., 1997, p.8). It is an activity that can become highly complex and there is a need for structure within it, often relating to the requirements and deadlines of an organisation (Tovey, 1997, p.13). Wilson (2011, p.58) developed a design process model and outlined the main activities as being need/requirements, research, ideas generation, design development, design realisation/finished design, and evaluation. These stages will be referred to within the pilot study findings (see Section 6) in order to relate the tasks undertaken back to a recognised design process model.

\subsection{FOOTWEAR}

Footwear design has a number of possible approaches and is not linear. Different companies/designers undertake it differently, depending on product type, market and personal preferences. The paper focuses on design for manufacture as opposed to designer/makers, where the finished design is also the finished product (Schaffer et al., 2012, p.157) as opposed to a model to be followed or adapted for production. Footwear requires a balance of creativity and functionality (Glanville et al., 1934, p.103); it "combines a full spectrum of concerns," and a successful design is "both an appealing object and a feat of engineering" (Huey et al., 2007, p.165). With such complex products, accuracy and detail is key (Schaffer et al., 2012, p.121) and this is reflected in the design process. CAD/CAM is not currently prevalent in footwear design and tasks are generally performed by hand (Zequn et al., 2010, p.222; Antemie et al., 2012, p.415) but potential for digital methods have been identified to improve speed (Antemie et al., 2012, p.415) and flexibility in design (Azariadis, 2013, p.337).

\subsection{TEXTILES}

Wilson (2001) presents a comprehensive overview of the textile design process, where the main function is described as to "design and produce, to an agreed timetable, an agreed number of commercially viable fabric designs" (Wilson, 2001, p.10). The design process is usually one of intuition, based on experience and there is a certain amount of trial and error (Adanur et al., 2013, p.716), but while there is an opportunity to generate unexpected results on the loom (Wilson, 2001, p.15) woven textiles rely on a great deal of planning (Bate et al., 2014). Weavers must work within the constraints of the warp, but use creativity, intuition and judgment to make decisions (Hemmings, 2012, p.7). The processes can differ for printed and constructed textiles due to variations in requirements and they will also differ based on the preference of the designer (Wilson, 2001, p.28). Previous stages may be revisited when appropriate. Digital design practices have been adopted by many textile designers and often, hands-on/digital hybrid approaches are used (Braddock-Clarke et al., 2012, p.8), allowing the designer to take advantage of the benefits associated with both (Philpott, 2012, p.69). The use of Adobe Photoshop and Illustrator has become standard practice within the creative textile design industry (Bowles et al., 2009, p.7) and parametric approaches are also being explored, mainly within technical textiles (see Adanur et al., 2013; Khabazi, 2010). The benefits or potential benefits of this method include the ability to predict the behaviour and properties of a fabric, thereby providing greater efficiency in time and labour (Adanur et al., 2013, p.716). Another notable advance in the design process is the development of 3D printed textiles, which have become useable for the ready-to-wear fashion market. For example in Pringle of Scotland's AW14 collection panels of 3D printed textile were incorporated into garments (Dezeen, 2014).

Referring to these examples it is evident that CAD/CAM is currently used and is being explored within textile design and to a lesser extent, footwear design. This raises the question as to whether hands-on textile approaches are still relevant? A theoretical case for its use is presented in the following section.

\section{DESI GNER BEHAVI OUR AND THE CREATI VE DESI GN PROCESS}

Cross (1982, p.226) describes how designers solve "ill-defined" problems with a focus on the solution using "constructive" modes of thinking. They explore the problem and solution in parallel (Cross, 2004, p. 432; Lawson et al., 1997, p. 176) and patterns are synthesised rather than identified with solutions being 


\section{Weave as a method of sandal design: I nnovation through the integration of a hands-on woven textile approach}

constructed by the designer (Cross, 1982, p.224). Such views, which seem to have become commonly accepted within design research, all point to the prevalence of ambiguity and uncertainty in the design process.

Whilst experience aids the ability to interpret and use high levels of ambiguity, coping mechanisms must be employed by designers in order to manage these complex problems. During the design process, a number of cognitive actions are used in conjunction with one another (Sennett, 2009, p.153) or in close sequence, being frequently switched from one to another. Schön (1992, p.7) describes this switching as the actions of "seeingmoving-seeing" as a method of managing the lack of ability to preconceive all of the consequences of an action. Schön $(1992$, p.5) also describes how design solutions are obtained through the construction and reconstruction of objects. This can be achieved via a number of methods, using digital or analogue representation, or by physically making them.

The construction and reconstruction of objects along with cyclical cognitive actions form a common approach to design practice (Schön, 1992, p.5). Such an approach can conceivably lead to repetition, and this, along with hands-on interaction, cannot only facilitate the discovery of a design solution but also generate embodied knowledge of processes and materials (Philpott, 2012, p.69; Sennett, 2009, p.160). Cross (1982, p.225) stated that designers can gain primary knowledge from objects and materials along with generating knowledge through designing them. It has since become widely accepted that a wealth of information can be gleaned from interaction with and the making of objects (Cross, 2001, p. 54-55; Leader, 2010, p. 408; Philpott, 2012, p. 56; Sweet, 2013, p. 32), this theory was evident within the case study.

Schön (1992, p.4) puts forward the theory that an understanding of a design situation can be gained through sensory appreciation, be it in representational forms (digital or non-digital) or by first-hand experience. However, it has been argued by Gallace et al. (2011, p.569) that interaction through touch gives a more intimate and active experience than sight does; it is notable that many representational forms rely on sight over touch. In this respect, it could be argued that designing through making actual objects provides a more indepth knowledge of that design. Knowledge gained through making can inform future designs (Sweet, 2013, p.38; Philpott, 2012, p.69) and make sense of representations of objects, enhancing the ability to think threedimensionally (Sennett, 2009, p.153). This leads the authors to query whether making and interacting with materials can lead to innovations beyond those developed using representational media. Which is plausible due to the generation of in-depth knowledge gained as opposed to relying on prior understanding.

There are usually a number of common constraints that must be considered by designers. They are "constrained to produce a practicable result within a specific time limit," (Cross, 1982, p.224) meaning that whatever approach is used, it must be time sensitive and able to be put into practice in whatever market or capacity is intended. Additional concerns include, price range, manufacturing possibilities, suitability for the intended consumer (Wilson, 2001, p. 14) along with range building and ease of production (Leader, 2010, p.405). Successful communication of an idea is another key consideration as design is an activity that is often undertaken by a team of people rather than an individual (Lawson et al., 1997, p.176). When developing and evaluating novel methods of sandal design, these key considerations must be taken into account.

\section{TEXTI LE/ CRAFT-BASED APPROACHES AND LOGIC}

Valentine (2011, p.285) describes how popular culture still views craft as a "hobbyist pursuit". However, there is much intellectual value which comes from continued practice with the ability to "develop self-knowledge directly impact[ing] on levels of innovation" (Valentine, 2011, p.285). Philpott (2012, p.56) puts forward the theory that interaction with materials leads to innovation and it is this theory that has potential use in sandal design. The use of craft-based methods for generating design ideas and translating them into a "practicable result" (Cross, 1982, p.224) could provide benefits to the end product. Potentially leading to the development of sandal uppers that can be woven as one piece, with little or no cutting and stitching required, reducing labour cost and waste.

While weaving is often referred to as a craft practice, the final outcome of the proposed approach will not be an individual object. The focus is on the ability for making to aid the early design stage with the opportunity for innovation as described by Philpott $(2012$, p.56) and Valentine $(2011$, p.285). Some may argue that this does not provide the benefits of craft and that in order to create beautiful products, the whole process, including 


\section{Weave as a method of sandal design: I nnovation through the integration of a hands-on woven textile approach}

production must remain a craft activity, involving risk and producing individual outcomes (Pye, 1968, p.4). However, it seems that there is potential for craft processes to aid the generation of novel ideas that are of value to the design of a product, even if it is scaled up for mass manufacture.

In the discipline of textiles, touch is important (Philpott, 2012, p.54) and woven textiles are often designed by making actual fabric samples. This is dependent on the context and constraints of the process/outcomes, and although CAD is used, it is common to construct fabrics during the design process due to the importance of the feel, handle and construction of materials (Wilson, 2001, p.14-15).

Oxman (2012) reports on an increasing interest in the role of materials in design and presents a theory of "informed tectonics" where there is an informed relationship between design, material and structure. This method of design is likened to vernacular crafts such as weaving and the report describes how the logic of such crafts can be extended to be used within a number of design disciplines. This way of thinking can also incorporate the utilisation of digital design and construction processes by using them to create a single process that incorporates design, fabrication, production and manufacturing using craft-based principles (Oxman, 2012, p.450). So it is possible to see the potential for craft-based approaches to be developed into digital ones. However, this may impact on the levels of innovation that can be achieved through an intimate understanding of constructions and materials.

\section{APPROACHES TO THE DESIGN PROCESS}

In order to investigate a craft-based approach to sandal design an action research case study was undertaken in the form of a design project. Sandal uppers were created through the medium of woven textiles. It involved data collection through recording diary entries at the end of a day of designing, as informed by Pedgley (1997, p.220-221). The data was analysed through coding and clustering, informed by Dey (1993) and Eisenhardt (2002).

Tasks were categorised independently of outcomes/consequences/what was involved and the relationship/links between them were investigated. Tasks were assigned to a stage of the design process and then divided by the type of approach used. The approach refers to whether they were 2D or 3D and digital, non-digital or hybrid. This allowed the process to be investigated in terms of these categories.

The second stage of categorisation involved the outcomes/consequences/what was involved. It included the labels 'material/physical understanding' and 'focus/inspiration/exploration' among a number of others relating to the data. They were categorised and linked to the approaches used. Three types of link were identified, led to/provided/aided, involved/used and informed. It was possible to apply these links to the majority of the data, thereby viewing them in relation to one another.

The paper focuses on two stages of the design process outlined by Wilson (2011, p.58), the "research" and "ideas generation" stages. These were the two main areas addressed within the pilot study, with the "need/requirement" stage having taken place before the case study commenced and the latter stages being areas for future research.

During the research stage three different approaches were used:

$-2 \mathrm{D}$ digital

- 2D hybrid

- 3D hands-on

2D digital approaches included the creation of creating digital inspiration/mood boards. This aided the development of a theme and provided focus and direction for the product to be designed. It also provided inspiration, informing subsequent stages of the design process. A huge amount of imagery was readily available online, initially this led to excess information but it also provided efficiency. Figure 2 shows an example of an outcome in the form of a digital mood board.

2D hybrid approaches were utilised to generate and refine a colour palette. The non-digital aspects provided benefits in accuracy of shade/tone but sometimes lacked time efficiency. Digital methods were integrated to 


\section{Weave as a method of sandal design: Innovation through the integration of a hands-on woven textile approach}

improve efficiency, however, this impacted on accuracy. Figure 3 shows an example of a non-digital collage techniques, used alongside digital imagery and colour picking techniques.

3D hands-on research was initially used to explore potential yarns. It involved testing and decisions made through tacit judgement, gauging the suitability of materials. As discussed in Section 3, stages of the design process may be revisited and this was the case here. Towards the latter part of the case study, nylon yarns were tested through weaving and finishing processes. An understanding of the behaviour of potential materials was gained and it will inform future work. It also highlighted the potential for hands-on processes to be used to explore materials, providing inspiration and potential for innovation through exploiting the properties of those materials. Along with these insights, data analysis revealed that the most prominent function of 3D hands-on research was indeed 'material/physical understanding', contrasting with the two other approaches, both being 'focus/inspiration/exploration'.

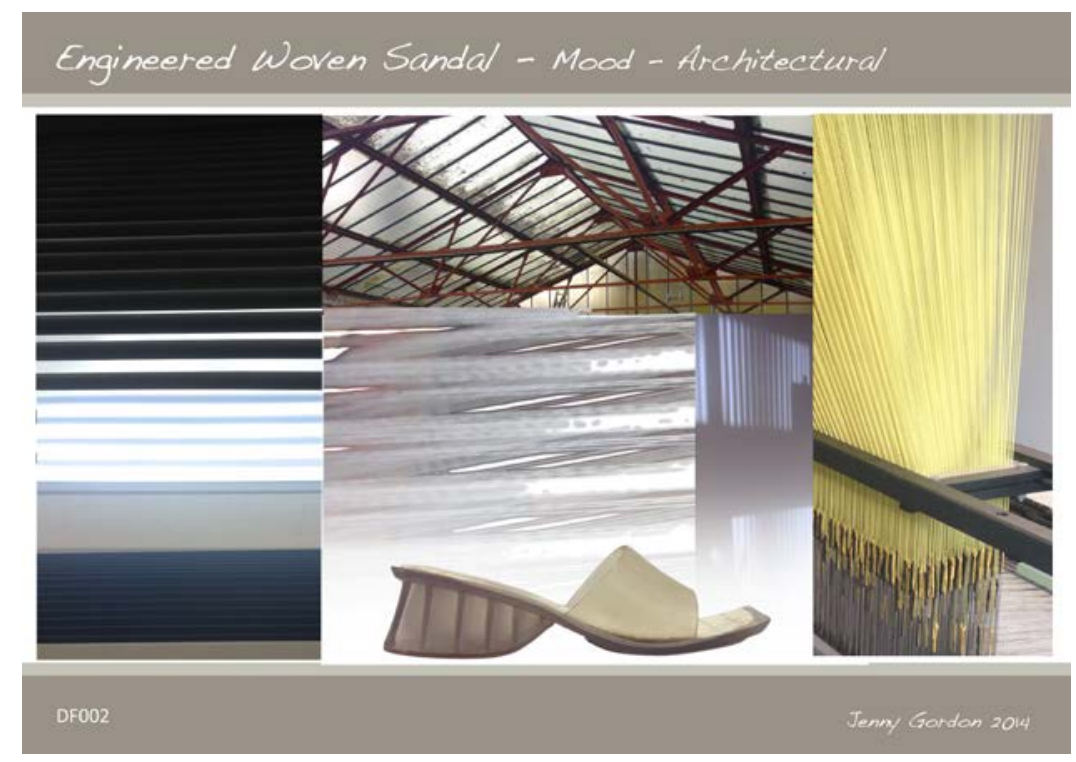

Figure 2- Example of a 2D digital research outcome
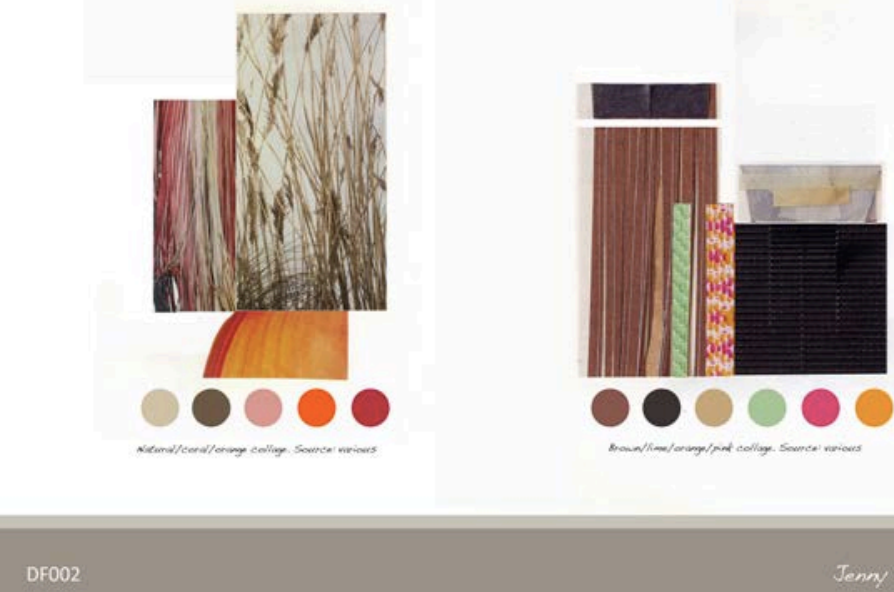

Figure 3- Example of a 2D hybrid approach outcome 


\section{Weave as a method of sandal design: Innovation through the integration of a hands-on woven textile approach}

The idea generation stage also revealed some initial insights. This stage of the design process also consisted of three approaches:

$-2 \mathrm{D}$ hybrid

- 3D hands-on

$-2 \mathrm{D}$ non-digital

$2 \mathrm{D}$ hybrid idea generation involved drawing. Sketching was used to perform the more intuitive aspects and CAD was introduced to perform the more precise tasks. An example of a CAD template that has been sketched into, alongside a sandal design (also sketched) is shown in Figure 4.

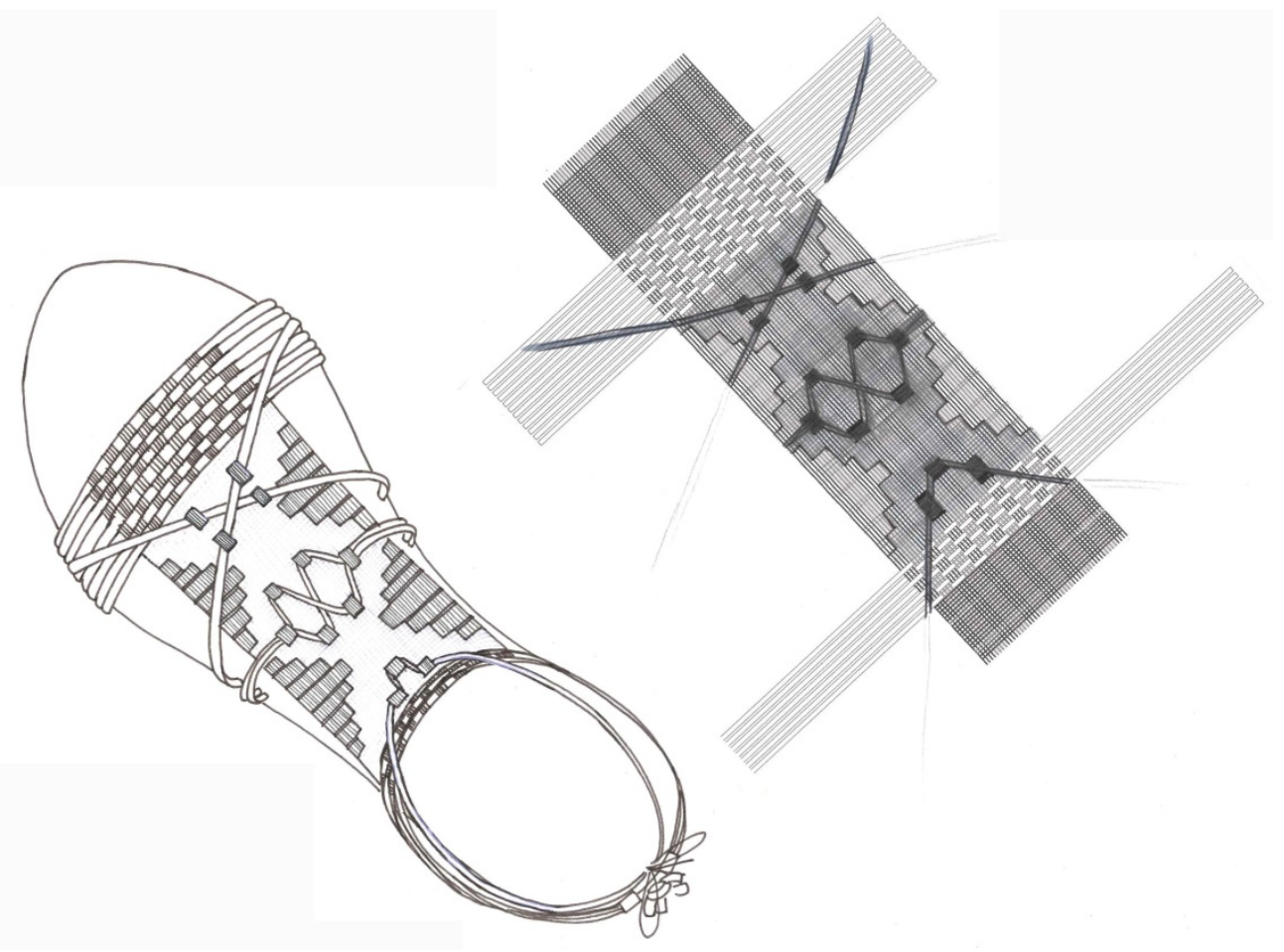

Figure 4- A 2D sketch of a sandal design alongside a CAD template of a weave design that has been sketched into

3D hands-on idea generation was undertaken using two methods, model making with paper and weaving on six-shaft floor loom. Model making aided idea generation, planning and visualisation, it was time and cost efficient. However, as it was representational it did lack the generation of in-depth knowledge of materials. In some instances weaving was used to visualise and evolve design ideas that had been conceived using 2D approaches. On the loom the construction and materials could be understood in more depth. In some cases ideas were generated on the loom, with some designs inspiring future ideas. These evolutions were either trialled straight away on the loom or quick models were made first on the last ${ }^{1}$ in order to gain a clearer idea of measurements.

2D non-digital design was also used, this relied on prior knowledge but it was more time efficient than the hybrid approach.

During the case study, concerns arose over the presentation of 3D designs. The sketches generated using 2D approaches were not accurate due to the designs evolving on the loom and they were not presentable. In order to address the issue the uppers were photographed on a clear vacuum form of a last before being digitally

${ }^{1} \mathrm{~A}$ last is the $3 \mathrm{D}$ form that footwear is constructed around providing its shape 
Weave as a method of sandal design: I nnovation through the integration of a hands-on woven textile approach

placed onto the outsole design (see Figure 5). This digital approach was integral in bringing the designs together for coherent presentation.

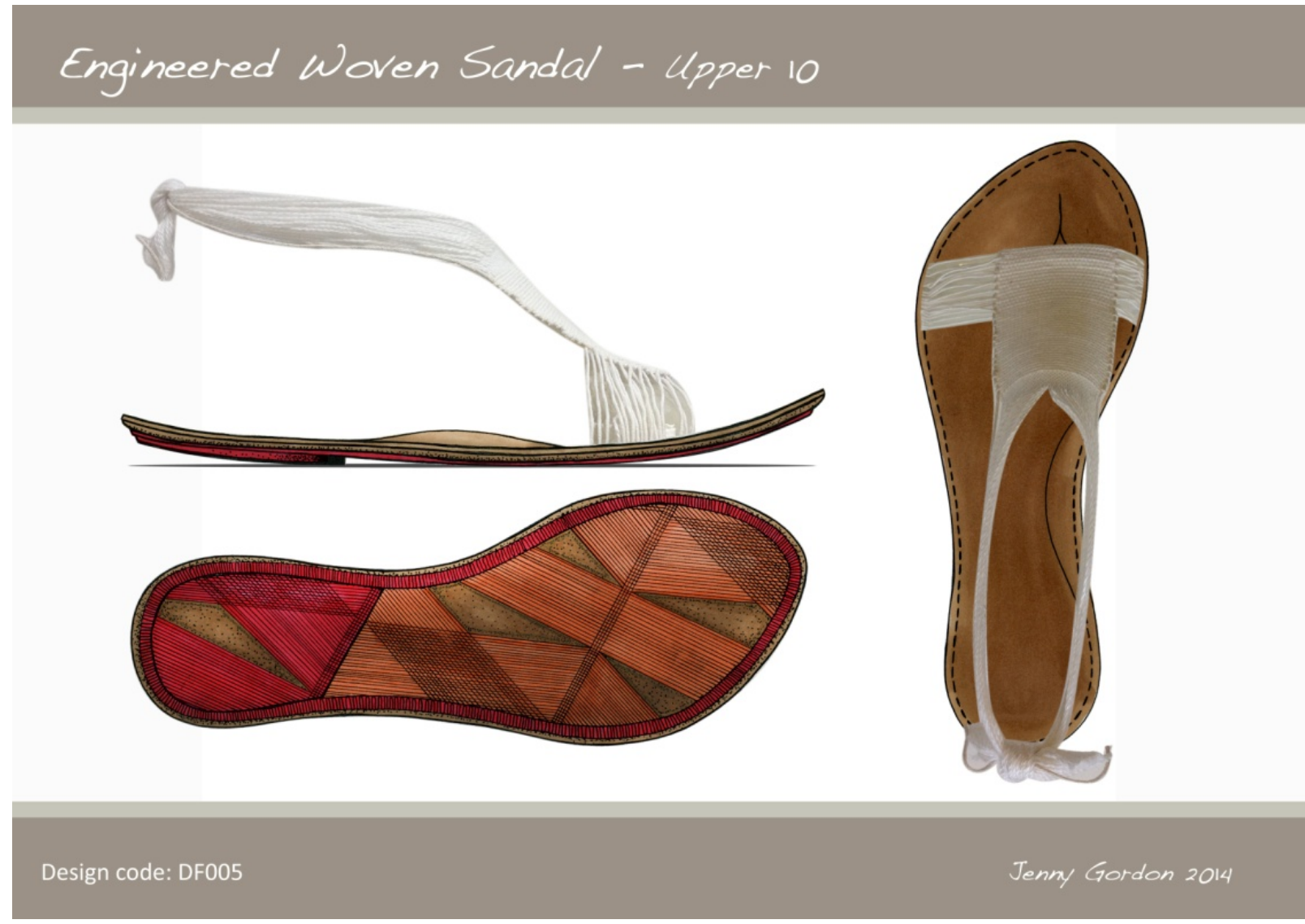

Figure 5- An upper and sole design incorporated and presented digitally

\section{CONCLUSI ONS}

Craft-based processes explore form, construction and material as a single process whereas typical methods of footwear design explore them sequentially, and although stages may be revisited, they are generally performed as separate actions (Schaffer et al., 2012, p.120-159). Figure 6 shows these approaches in relation to one another. This logic may be applied to digital approaches, however, the same benefits may not be seen with regards to innovation and knowledge gain. Empirical evidence revealed potential for CAD to bring together designs that were created in a number of formats for coherent presentation. 


\section{Weave as a method of sandal design: I nnovation through the integration of a hands-on woven textile approach}

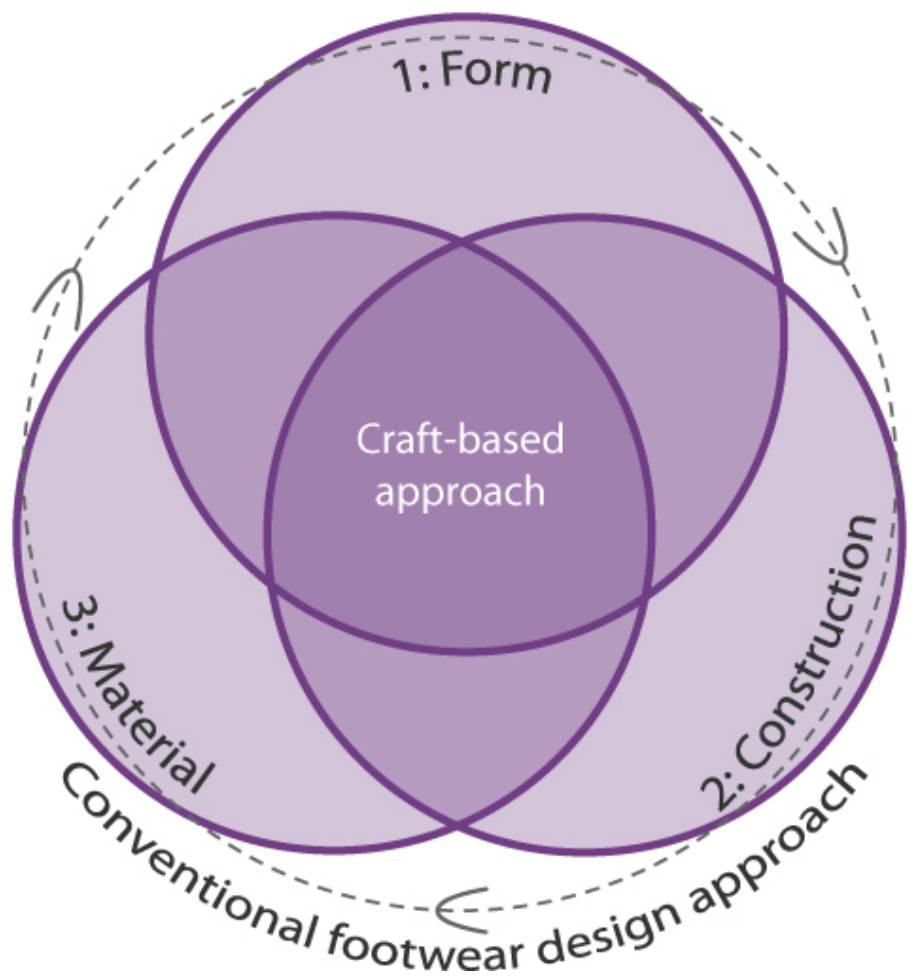

Figure 6- A Venn diagram showing a craft-based approach in comparison to more typical footwear design

It has been identified that a craft-based approach is applicable under some, but not all circumstances. Where innovations in construction and materials are important to design, it can be argued that hands-on design methods provide benefits. The introduction of automated manufacture means that there is potential to produce woven textile sandal uppers on a mass scale. A Hands-on approach has been identified as having the potential to aid creativity; this could impact positively on the sandal industry, in the form of economic growth (Lommerse et al., 2011, p.388). Ambiguity and uncertainty were identified as being integral to the design process. Handson approaches may provide high levels of uncertainty through the introduction of increased risk. Initial research suggests that its main benefits lie in providing an in-depth knowledge of constructions and materials. This can inform future work, providing potential for innovation through knowledge and understanding. Such an approach may create a commercial output for skilled craftspeople. There is potential for collaboration, giving craft practitioners a commercial outlet for their work and design teams the knowledge and experience needed in order to execute innovations within a craft-based medium. There is a conceived need for the integration of craft practitioners within product design/development teams (Wallace et al., 2004). This is something that future work into craft-based approaches to design may help to facilitate.

\section{REFFERENCES}

Adanur, S. and Vakalapudi, J. S. (2013) Woven fabric design and analysis in 3D virtual reality. Part 1: computer aided design and modeling of interlaced structures. Journal of the Textile Institute 104 (7), pp. 715-723.

Antemie, A., Harnagea, F. and Popp, A. (2012) Advanced virtual footwear design, by rendering shoe models, instead of drawing. In: Proceedings of The 8th International Scientific Conference eLearning and software for Education. Bucharest, 26th-27th April 2012. Frankfurt: C.E.E.O.L., pp. 414-421.

Azariadis, P. (2013) Finite Element Analysis Methods in Footwear Design. In: ed. by Goonetilleke, R. S. The Science of Footwear. Boca Raton: CRC Press, pp. 321-340. 


\section{Weave as a method of sandal design: Innovation through the integration of a hands-on woven textile approach}

Bate, G. and Rudman, D. (2014) Artist: Anastasia Azure, Providence, Rhode Island, USA. [online]. (Accessed 16th January 2014) Available from: http: / / www . worldofthreadsfestival . com / artist \% 5C _ interviews / \%046 \% 5C _ anastasia\%5C_azure\%5C_12.html.

Bowles, M. and Isaac, C. (2009) Digital textile design. London: Laurence King.

Braddock-Clarke, S. E. and Harris, J. (2012) Digital visions for fashion + textiles: made in code. London: Thames \& Hudson.

Cohen, A. M. (2011) Fast fashion: Tale of two markets. The Futurist, pp. 12-13.

Collis, A., Hiley, A. and Wilson, J. A. (2007) Through the wardrobe: a generic plat- form to foster the evolution of creative problem solving skills. In: Proceedings of Creative Conference 07: Creativity or Conformity? Building Cultures of Creativity in Higher Education. Cardiff. Cardiff: Cardiff Metropolitan University, pp. 1-6.

Cross, N. (1982) Designerly ways of knowing. Design Studies 3 (4), pp. 221-227.

Cross, N. (2001) Designerly ways of knowing: design discipline versus design science. English. Design Issues 17 (3), pp. 4955.

Cross, N. (2004) Expertise in design: an overview. Design Studies 25 (5), pp. 427- 441.

Dey, I. (1993) Qualitative data analysis a user-friendly guide for social scientists. London: Routledge.

Dezeen (2014) 3D-printed fabrics by Richard Beckett woven into Pringle of Scotland's ready to wear garments. [online]. (Accessed 4th August 2014) Available from: http://www.dezeen.com/2014/02/17/3d-printed-fabrics-by-richardbeckett-woven-into-pringle-of-scotlands-ready-to-wear-garments/.

Eisenhardt, K. M. (2002) Building Theories From Case Study Research. In: ed. by Huberman, M. and Miles, M. B. The Qualitative Researchers Companion. London: Sage Publications, pp. 5-35.

Gallace, A. and Spence, C. (2011) Tactile aesthetics: towards a definition of its characteristics and neural correlates. Social Semiotics 21 (4), pp. 569-589.

Glanville, F. Y., Worswick, B. and Golding, F. Y. (1934) Boots and shoes: their making, manufacture and selling, Vol.1: Pattern cutting and making. London: Pitman.

Hemmings, J. (2012) Warp \& weft: woven textiles in fashion, art and interiors. London: Bloomsbury.

Huey, S. and Proctor, R. (2007) New shoes: contemporary footwear design. London: Laurence King.

Khabazi, Z. (2010) Generative algorithms concepts and experiments: weaving. [online].(Accessed 11th December 2013) Available from: http://www.grasshopper3d.com/page/tutorials- 1.

Lawson, B. and Loke, S. M. (1997) Computers, words and pictures. Design Studies 18 (2), pp. 171-183.

Leader, E. (2010) Materializing craft: Evaluating the effects of experiencing actual materials during the design process. Design Principles and Practices 4 (4), pp. 405-418.

Lommerse, M., Eggleston, R. and Brankovic, K. (2011) Designing Futures: A Model for Innovation, Growth and Sustainability of the Craft and Design Industry. Design Principles and Practices 5 (4), pp. 385-404.

O'Keeffe, L. (1996) Shoes: a celebration of pumps, sandals, slippers and more. New York: Workman.

Oxman, R. (2012) Informed tectonics in material-based design. Design Studies 33 (5), pp. 427-455.

Patriquin, M. (2012) One shoe after the other: how Montreal-based Aldo built a sprawling, ruthlessly efficient footwear empire. Maclean's 125 (43), pp. 41-42. 


\section{Weave as a method of sandal design: I nnovation through the integration of a hands-on woven textile approach}

Pedgley, O. F. (1997) Towards a method for documenting industrial design activity from the designer's perspective. In: Proceedings of IDATER 97, Loughborough. Loughborough: Loughborough University Department of Design and Technol- ogy, pp. 217-222.

Philpott, R. (2012) Crafting innovation: The intersection of craft and technology in the production of contemporary textiles. Craft Research 3 (1), pp. 53-74.

Posselt, E. A. (1917) Hand books of the textile industry, vol. 2: Narrow woven fabrics. Philadelphia: Textile Publishing Company.

Pye, D. (1968) The nature and art of workmanship. London: Cambridge University Press.

Schaffer, J. and Saunders, S. (2012) Fashion design course. Accessories: design practice and processes for creating hats, bags, shoes and more. London: Thames and Hudson.

Schön, D. A. (1992) Designing as reflective conversation with the materials of a design situation. Knowledge-Based Systems 5(1), pp. 3-14.

Sennett, R. (2009) The craftsman. London: Penguin.

Shillito, A. M. et al. (2001) 'Tacitus' project: identifying multi-sensory perceptions in creative 3D practice for the development of a haptic computing system for applied artists. Digital Creativity 12 (4), pp. 195-204.

Sweet, T. (2013) Instilling an awareness of phenomenology through a craft-centered design pedagogy. International Journal of Design Education 6 (2), pp. 31-39.

Thompson, A. and Dick, S. (1952) Narrow fabric weaving. Manchester: Harlequin Press.

Thornton, J. H. (1970) Textbook of footwear manufacture. 3rd. London: Butterworth and Co.

Tovey, M. (1997) Styling and design: intuition and analysis in industrial design. Design Studies 18 (1), pp. 5-31.

Treadaway, C. (2007) Digital crafting and crafting the digital. Design Journal 10 (2), pp. 35-48.

Valentine, L. (2011) Craft as a Form of Mindful Inquiry. Design Journal 14 (3), pp. 283-306.

Verdu-J over, A. et al. (2008) Alternative value creation strategies in the footwear industry: Exploring the role of production offshoring. In: 2008 IEEE International Conference on Industrial Engineering and Engineering Management. Singapore. IEEE, pp. 1880-1884.

Waddell, G. (2004) How fashion works: couture, ready to wear and mass production. Oxford: Blackwell Science.

Wallace, J. and Press, M. (2004) All this useless beauty: the case for craft practice in design for a digital age. The Design Journal 7, pp. 42-53.

Wilson, J. A. (2001) A Handbook of Textile Design: Principle, Process and Practice. Cambridge: Woodhead Publishing.

Wilson, J. A. (2011) Core Design Aspects. PhD thesis. The University of Manchester.

Yair, K. and Schwarz, M. (2011) Making value: Craft in changing times. Cultural Trends 20 (3-4), pp. 309-316.

Zequn, M. and Rui, G. (2010) The direction of footwear computer-aided design in China. In: Proceedings of Computer-Aided Industrial Design \& Conceptual Design (CAIDCD), IEEE 11th International Conference on. Vol. 1. Yiwu: IEEE, pp. 222-225. 